\title{
PELARANGAN CANTRANG: STRATEGI PENGEMBANGAN KEBERLANJUTAN SUMBERDAYA IKAN DI TELUK LAMPUNG
}

\section{CANTRANG BAN: FISH RESOURCE SUSTAINABILITY DEVELOPMENT STRATEGY IN LAMPUNG BAY}

\author{
Debi Hardian $^{1, *}$, Indra Gumay Febryano², Supono², \\ Abdullah Aman Damai ${ }^{2}$ dan Gunardi Djoko Winarno
}

\author{
${ }^{1}$ Dinas Kelautan dan Perikanan Provinsi Lampung, Bandar Lampung \\ Jl. Drs. Warsito No.76, Talang, Kec. Telukbetung Selatan, Lampung 35221 Indonesia \\ ${ }^{2}$ Magister Manajemen Wilayah Pesisir dan Laut, Universitas Lampung \\ Jl. Prof. Dr. Soemantri Brojonegoro No 1, Bandar Lampung 35145 Indonesia \\ Email: hardiandebi@yahoo.com
}

\begin{abstract}
ABSTRAK
Cantrang merupakan alat tangkap ikan yang telah dilarang penggunaannya di seluruh wilayah Indonesia. Kebijakan ini telah menimbulkan pro kontra dalam implementasinya dimasyarakat. Tujuan penelitian adalah untuk menganalisis strategi pengembangan implementasi kebijakan pelarangan alat tangkap cantrang di Teluk Lampung. Pengumpulan data dilakukan dengan wawancara, observasi dan studi dokumentasi. Data yang terkumpul selanjutnya dianalisis kekuatan, kelemahan, peluang dan ancaman menggunakan Analisis SWOT untuk strategi pengembangan implementasi kebijakannya. Hasil penelitian menunjukkan strategi yang terpilih adalah strategi yang memanfaatkan kekuatan dengan mengurangi ancaman yang ada. Strategi ini mendukung strategi diversifikasi melalui peningkatan kepatuhan nelayan dalam penggunaan alat tangkap ikan dan peningkatan lapangan kerja.
\end{abstract}

Kata Kunci: alat tangkap ikan, cantrang, implementasi kebijakan, SWOT, Teluk Lampung

\section{ABSTRACT}

Cantrang is a fishing gear which has been banned in all region of Indonesia.This policy leads pros and cons in implementation within community. The purpose of this study is to analyze the strategy of implementation development about cantrang prohibition policy in Lampung Bay. Data were collected by interview, observation, and documentation. These dat will be analyzed strengths, weaknesses, opportunities, threats by SWOT analysis to strategic the development of policy implementation. The result of this study shows that strategy with strength and reducing the threat is selected. This strategy support the diversification strategy through uplifting the fishing gear and working field.

Keywords: fishing gear, cantrang, policy implementation, SWOT, Lampung Bay

\section{PENDAHULUAN}

Potensi kelautan dan perikanan Indonesia sangat besar, dapat dimanfaatkan untuk meningkatkan perekonomian nelayan walaupun pada kenyataannya belum dapat mengurangi tingkat kemiskinan masyarakat pesisir (Dahuri, 2003; Sukmawati, 2008; Andryana, 2016). Salah satu pemanfaatan sumberdaya perikanan dilakukan dengan penangkapan ikan memakai berbagai macam alat tangkap yang mempunyai produktivitas dan area penangkapan yang berbeda. Pemakaian alat tangkap umumnya berdasarkan kebiasaan masyarakat setempat dan ilmu turun temurun.

Nelayan memilih alat tangkap sesuai dengan keahlian dan kemampuan biaya operasionalnya. Jenis alat tangkap yang digunakan menentukan jenis dan jumlah ikan yang ditangkap. Tingkat produktivitas alat tangkap dapat mempengaruhi tingkat kesejahteraan nelayan (Aji et al., 2013). Salah satu alat tangkap yang disukai nelayan adalah alat tangkap cantrang yang dinilai mempunyai produktivitas tinggi, biaya alat tangkapnya lebih murah dan perawatan alat tangkap relatif mudah (Yapanani et al., 2013). Cantrang adalah alat tangkap 
berbentuk jaring, mempunyai sayap, badan dan kantong, tidak menggunakan pembuka jaring, area penangkapan di daerah perairan yang dasarnya datar dengan substrat berlumpur atau berpasir, tidak berbatu karang (Bambang, 2006).

Dalam perjalanannya alat tangkap cantrang dianggap dapat mengakibatkan degradatif dan destruktif terhadap lingkungan dan sumberdaya ikan. Saat ini, pemanfaatan kekayaan kelautan dikuatirkan mempercepat penurunan daya dukung sumberdaya ikan maupun ekosistem. Menurut FAO dalam Satria (2015), 90\% stok perikanan dunia dalam kondisi mengkuatirkan, $61 \%$ sudah mengalami tangkap penuh (fully exploited) dan 29\% sisanya tangkap lebih (over exploited). Begitu pula tingkat kerusakan mangrove 3-5 kali dari laju deforestasi. Sekitar 29\% padang lamun juga telah rusak. Kerusakan terumbu karang dunia mencapai $50 \%$ dan pada tahun 2050 dengan kenaikan suhu seperti saat ini maka terumbu karang akan musnah.

Menurut berbagai kalangan, cantrang merupakan alat penangkapan ikan yang dapat merusak keberlanjutan sumberdaya ikan dan lingkungan serta menimbulkan masalah sosial dari perebutan area penangkapan ikan. Operasional cantrang yang dilakukan dengan penarikan jaring di dasar perairan menimbulkan dampak signifikan terhadap ekosistem dasar bawah laut. Penarikan jaring menyebabkan terjadi pengadukan dasar perairan yang dapat menimbulkan kerusakan dasar perairan (Zamroni, 2015; Zuliyati, 2015). Tetapi beberapa kalangan terutama nelayan menilai bahwa cantrang sesuai spesifikasi teknisnya tidak membahayakan sumberdaya ikan dan lingkungan.

Pemanfaatan sumberdaya ikan mesti diiringi dengan kebijakan agar tidak terjadi kerusakan pada lingkungan, penurunan sumberdaya ikan dan ekosistem. Kebijakan sengaja dilakukan untuk memecahkan suatu masalah tertentu (Wahab, 2012). Pelaksanaan kebijakan merupakan salah satu yang diidentifikasi dalam lingkup proses terjadinya kebijakan (Kartodihardjo, 2017). Analisis dan implementasi merupakan tahap yang sangat menentukan dalam proses pembuatan kebijakan (Dunn,1991).

Untuk pengendalian dan mengatasi penurunan sumberdaya ikan dan lingkungan, pemerintah telah menetapkan kebijakan pelarangan cantrang melalui Peraturan Menteri Kelautan dan Perikanan RI Nomor :
71/Permen-KP/2016. Kebijakan pelarangan cantrang merupakan salah satu upaya untuk keberlanjutan sumberdaya ikan di perairan Indonesia. Perairan Lampung dengan panjang garis pantai $1.105 \mathrm{~km}$ merupakan salah satu potensi yang besar di bidang perikanan yang mesti dijaga kelestariannya. Teluk Lampung merupakan salah satu wilayah fishing ground dan home base penangkapan ikan dengan alat tangkap cantrang. Dengan demikian perlu dilakukan penelitian di Teluk Lampung untuk melihat hubungan keberlanjutan sumberdaya ikan dengan pelarangan alat tangkap cantrang. Tujuan penelitian adalah merumuskan strategi pengembangan keberlanjutan sumberdaya ikan di Teluk Lampung.

\section{METODE PENELITIAN}

Penelitian dilakukan di Pelabuhan Perikanan Pantai Lempasing Kota Bandar Lampung. Penelitian dilaksanakan selama 6 (enam) bulan yaitu pada bulan Februari - Juli 2019. Alat yang digunakan dalam penelitian ini adalah alat tulis, kamera, laptop dan kuesioner. Objek penelitian adalah nelayan dan aparatur pemerintah. Pengumpulan data dilakukan dengan wawancara, Focus Group Discussion (FGD), observasi, dan studi dokumentasi. Pengambilan sampel responden dari pihak pemerintah (agen pelaksana) dan pembina/pemilik kapal dilakukan dengan purposive sampling (sengaja), yaitu individu yang secara langsung terkait dengan kebijakan pelarangan alat tangkap cantrang. Pengambilan secara purposive ini diartikan sebagai pengambilan responden sesuai dengan keadaan yang dikehendaki (Sugiyono, 2018). Jumlah responden penelitian ditentukan secara purposive sampling sebanyak 30 orang. Untuk merumuskan arahan strategi implementasi kebijakan pelarangan alat tangkap cantrang digunakan pendekatan analisis SWOT (Strength, Weaknesses, Opportunity, Threat). Analisis SWOT merupakan analisis faktor internal (kekuatan, kelemahan) dan faktor eksternal (peluang, ancaman). Menurut Rangkuti (2006), analisis SWOT adalah identifikasi berbagai faktor secara sistematis untuk merumuskan strategi pengembangan.

\section{HASIL DAN PEMBAHASAN}

Beberapa isu penting terkait dengan upaya keberlanjutan sumberdaya ikan di Teluk Lampung sebagai berikut : (1) Nelayan 
masih banyak yang menggunakan alat penangkapan ikan yang terlarang yang membahayakan keberlangsungan sumberdaya ikan dan lingkungan. (2) Alat penangkapan ikan yang ramah lingkungan belum tersosialisasi dengan baik dan belum diterima nelayan sepenuhnya. (3) Peran forum koordinasi pengawasan belum efektif. (4) Penegakan hukum masih diskriminasi dan tidak sama disemua wilayah. (5) Anggaran yang tersedia untuk pengawasan sumberdaya ikan kurang memadai. (6) Kepatuhan nelayan dalam penggunaan alat penangkapan ikan masih kurang. (7) Lapangan pekerjaan untuk nelayan masih terbatas. Komunikasi Pemerintah dengan nelayan masih kurang. (8) Kelembagaan kelompok nelayan masih kurang.

Berbagai permasalahan yang ada mesti diselesaikan dalam upaya keberlanjutan sumberdaya ikan. Strategi pengembangan keberlanjutan sumberdaya ikan melalui pelarangan cantrang dirumuskan melalui analisis SWOT yang meliputi analisis lingkungan internal (kekuatan dan kelemahan) dan eksternal (peluang dan ancaman).

Kekuatan yang mendukung implementasi kebijakan pelarangan alat tangkap cantrang sebagai berikut : (1) Adanya peraturan perundang-undangan yang melarang alat tangkap cantrang. (2) Adanya SDM untuk pelaksanaan kebijakan.
Adanya sarana dan prasarana. (4) Adanya forum koordinasi pengawasan.

Kelemahan yang dimiliki dalam implementasi kebijakan pelarangan alat tangkap cantrang adalah : (1) Implementasi peraturan yang tidak berlaku untuk semua wilayah. (2) Terbatasnya anggaran. Kebijakan bersifat "top-down". (3) Penerapan kebijakan membutuhkan waktu yang lama. (4) Komunikasi belum efektif antara pemerintah dan nelayan.

Peluang yang didapat dari eksternal merupakan pendukung terhadap implementasi kebijakan pelarangan alat tangkap cantrang, antara lain : (1) Permintaan ikan tinggi. (2) Adanya program dukungan peningkatan kesejahteraan nelayan. (3) Adanya alat tangkap ramah lingkungan sebagai pengganti cantrang. (4) Adanya dukungan untuk kelestarian sumberdaya ikan dan lingkungannya.

Ancaman yang datangnya dari lingkungan eksternal dalam implementasi kebijakan pelarangan alat tangkap cantrang sebagai berikut : (1) Bencana alam. (2) Adanya impor ikan. (3) Bertambahnya angka pengangguran. (4) Adanya potensi konflik nelayan dan kerawanan sosial. (5) Adanya tekanan politik pada implementasi kebijakan.

Setelah indikator-indikator di atas didapatkan, maka indikator kekuatan dan kelemahan diberi bobot dan rating, sehingga bisa dihitung jumlah kekuatan dan kelemahannya di dalam Tabel IFAS

Tabel 1. Faktor Strategi Internal (IFAS)

\begin{tabular}{|c|c|c|c|c|}
\hline Faktor-faktor Strategi Internal & Bobot & Rating & Bobot $\times$ Rating & Keterangan \\
\hline Kekuatan (S) : & & & & \multirow{5}{*}{$\begin{array}{l}\text { Permen KP } \\
\text { nomor } 71 \text { tahun } \\
2016\end{array}$} \\
\hline $\begin{array}{l}\text { 1. Adanya peraturan perundang- } \\
\text { undangan yang melarang alat } \\
\text { tangkap cantrang. }\end{array}$ & 0,20 & 4 & 0,80 & \\
\hline $\begin{array}{l}\text { 2. Adanya SDM untuk pelaksanaan } \\
\text { kebijakan. }\end{array}$ & 0,05 & 3 & 0,15 & \\
\hline 3. Adanya sarana dan prasarana. & 0,15 & 3 & 0,45 & \\
\hline $\begin{array}{l}\text { 4. Adanya forum koordinasi } \\
\text { pengawasan. }\end{array}$ & 0,15 & 4 & 0,60 & \\
\hline Jumlah Kekuatan (S) & 0,55 & & 2,00 & \\
\hline \multicolumn{5}{|l|}{ Kelemahan (W) : } \\
\hline 1. Implementasi peraturan yang & & & & \multirow{5}{*}{$\begin{array}{l}\text { Di Jawa Tengah } \\
\text { dan Jawa Timur } \\
\text { cantrang } \\
\text { diperboleh- kan }\end{array}$} \\
\hline wilayah. & $\begin{array}{l}0,15 \\
0,10\end{array}$ & $\begin{array}{l}3 \\
4\end{array}$ & $\begin{array}{l}0,45 \\
0,40\end{array}$ & \\
\hline 2. Terbatasnya anggaran. & 0,10 & 3 & 0,30 & \\
\hline $\begin{array}{l}\text { 3. Kebijakan bersifat"top-down". } \\
\text { 4. Penerapan kebijakan }\end{array}$ & 0,05 & 4 & 0,20 & \\
\hline $\begin{array}{l}\text { membutuhkan waktu yang lama. } \\
\text { 5. Komunikasi belum efektif antara } \\
\text { pemerintah dan nelayan. }\end{array}$ & 0,05 & 4 & 0,20 & \\
\hline Jumlah Kelemahan (W) & 0,45 & & 1,55 & \\
\hline
\end{tabular}


(Tabel 1). Penghitungan untuk Tabel EFAS (Tabel 2) dilakukan dengan cara yang sama dengan penghitungan pada Tabel IFAS di atas.

Bobot dimulai dari skala 1,0 (paling penting) sampai 0,0 (tidak penting) berdasarkan pengaruh faktor-faktor tersebut terhadap posisi strategis implementasi kebijakan pelarangan alat tangkap cantrang (semua bobot tersebut jumlahnya tidak boleh melebihi skor total $1,00)$. Rating dimulai dari skala 4 (outstanding) sampai dengan 1 (poor), berdasarkan pengaruh faktor tersebut terhadap kondisi implementasi kebijakan pelarangan alat tangkap cantrang. Variabel yang bersifat positif (semua variabel yang masuk kategori kekuatan) diberi nilai mulai dari +1 sampai dengan +4 (sangat baik) dengan membandingkannya dengan ratarata industri atau pesaing utama, sedangkan variabel yang bersifat negatif, kebalikannya (Rangkuti, 2013)

$$
\text { Diagram posisi strategi }
$$

pengembangan keberlanjutan sumberdaya ikan melalui pelarangan alat tangkap cantrang digambarkan berada pada Kuadran II mendukung strategi diversifikasi sebagaimana Gambar 1.

- Sumbu faktor internal $=\mathrm{S}-\mathrm{W}=2,00-$ $1,55=0,45$ (sumbu $X$ )
- Sumbu faktor eksternal $=$ O-T $=1,30$ $2,20=-0,90$ (sumbu $Y$ )

Dari penghitungan di atas, didapatkan strategi ST yaitu memanfaatkan kekuatan dengan mengurangi ancaman dalam strategi pengembangan keberlanjutan sumberdaya ikan melalui pelarangan alat tangkap cantrang.

Menentukan strategi implementasi kebijakan pelarangan alat tangkap cantrang digunakan matriks SWOT (Tabel 3). Strategi implementasi kebijakan pelarangan alat tangkap cantrang adalah strategi Strength and Threat (ST) yaitu memanfaatkan kekuatan untuk mengurangi ancaman yang ada. Strategi yang diterapkan dalam kondisi ini adalah mendukung strategi diversifikasi atau kompetitif melalui strategi berikut peningkatan kepatuhan nelayan dalam penggunaan alat tangkap ikan dan peningkatan lapangan kerja. Peningkatan kepatuhan nelayan dalam penggunaan alat tangkap ikan dapat dilakukan dengan peningkatan pengawasan, penambahan SDM dan anggaran pengawasan, peningkatan penegakan hukum, tidak adanya kebijakan dan penegakan hukum yang diskriminatif, peningkatan sosialisasi, pembinaan dan pendampingan, peningkatan peran forum koordinasi pengawasan dan kelembagaan kelompok

Tabel 2. Faktor Strategi Eksternal (EFAS)

\begin{tabular}{|c|c|c|c|c|}
\hline Faktor-faktor Strategi Eksternal & Bobot & Rating & Bobot $x$ Rating & Komentar \\
\hline Peluang (O): & & & & \multirow{5}{*}{$\begin{array}{l}\text { Kelestarian SDI } \\
\text { dan lingkungan } \\
\text { penting }\end{array}$} \\
\hline 1. Permintaan ikan tinggi. & 0,15 & 4 & 0,60 & \\
\hline $\begin{array}{l}\text { 2. Adanya program dukungan } \\
\text { peningkatan kesejahteraan } \\
\text { nelayan. }\end{array}$ & 0,10 & 4 & 0,40 & \\
\hline $\begin{array}{l}\text { 3. Adanya alat tangkap ramah } \\
\text { lingkungan sebagai pengganti } \\
\text { cantrang. }\end{array}$ & 0,05 & 3 & 0,15 & \\
\hline $\begin{array}{l}\text { 4. Adanya dukungan untuk } \\
\text { kelestarian SDI dan } \\
\text { lingkungannya. }\end{array}$ & 0,05 & 3 & 0,15 & \\
\hline Jumlah Peluang $(\mathrm{O})$ & 0,35 & & 1,30 & \\
\hline \multirow{7}{*}{$\begin{array}{l}\text { Ancaman }(\mathrm{T}) \text { : } \\
\text { 1. Bencana alam. } \\
\text { 2. Adanya impor ikan. } \\
\text { 3. Bertambahnya angka } \\
\text { pengangguran. } \\
\text { 4. Adanya potensi konflik nelayan } \\
\quad \text { dan kerawanan sosial. } \\
\text { 5. Adanya tekanan politik pada } \\
\text { implementasi kebijakan. }\end{array}$} & & & & \multirow{8}{*}{$\begin{array}{l}\text { Tingginya } \\
\text { tekanan politik } \\
\text { pada } \\
\text { implementasi } \\
\text { kebijakan }\end{array}$} \\
\hline & & & & \\
\hline & 0,05 & 4 & 0,20 & \\
\hline & 0,10 & 2 & 0,20 & \\
\hline & 0,20 & 3 & 0,60 & \\
\hline & 0,10 & 4 & 0,40 & \\
\hline & 0,20 & 4 & 0,80 & \\
\hline Jumlah Ancaman (T) & 0,65 & & 2,20 & \\
\hline
\end{tabular}




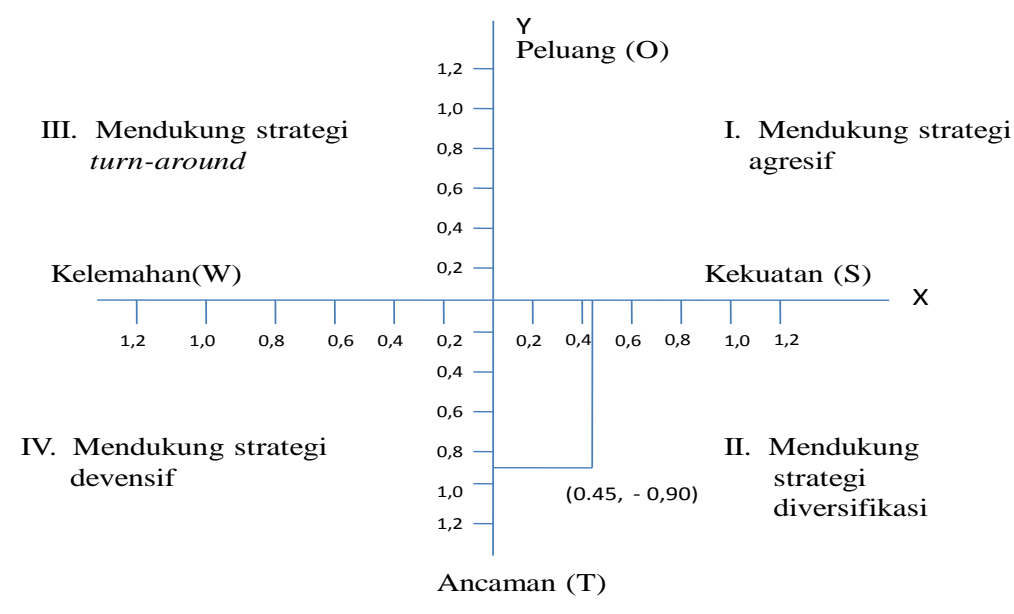

Gambar 1. Diagram Posisi Strategi Pengembangan Keberlanjutan Sumberdaya Ikan

Tabel 3. Matriks SWOT

\section{IFAS}

\section{Kekuatan (S)}

1. Adanya peraturan perundang-undangan yang melarang alat tangkap cantrang.

2. Adanya SDM untuk pelaksanaan kebijakan.

3. Adanya sarana dan prasarana.

4. Adanya forum koordinasi pengawasan.

\section{Kelemahan (W)}

1. Implementasi peraturan yang tidak berlaku untuk semua wilayah.

2. Terbatasnya anggaran.

3. Kebijakan bersifat"topdown".

4. Penerapan kebijakan membutuhkan waktu yang lama.

5. Komunikasi belum efektif antara pemerintah dan nelayan.

\section{EFAS}

\section{Peluang (0)}

1. Permintaan ikan tinggi.

2. Adanya program dukungan peningkatan kesejahteraan nelayan.

3. Adanya alat tangkap ramah lingkungan sebagai pengganti cantrang.

4. Adanya dukungan untuk kelestarian SDI dan lingkungannya.

\section{Ancaman ( $T$ )}

1. Bencana alam.

2. Adanya impor ikan.

3. Bertambahnya angka pengangguran.

4. Adanya potensi konflik nelayan dan kerawanan sosial.

5. Adanya tekanan politik pada implementasi kebijakan.

\section{ISU UTAMA (SO)}

1. Optimalisasi peran Forum Koordinasi Pengawasan

2. Peningkatan penggunaan alat tangkap yang ramah lingkungan

\section{ISU UTAMA (WO)}

1. Menegakkan hukum tanpa diskriminasi

2. Peningkatan anggaran pengawasan

\section{ISU UTAMA (ST)}

1. Peningkatan kepatuhan nelayan dalam penggunaan alat tangkap ikan

2. Peningkatan lapangan kerja

\section{ISU UTAMA (WT)}

1. Peningkatan komunikasi dengan nelayan

2. Peningkatan kelompok masyarakat 
nelayan, peningkatan komunikasi antara nelayan dan pemerintah serta pemangku kepentingan lainnya.

Peningkatan kepatuhan nelayan dalam penggunaan alat tangkap ikan perlu ditingkatkan agar sumberdaya ikan dan lingkungannya termasuk terumbu karang dapat dijaga untuk penangkapan berkelanjutan dapat dilakukan demi kepentingan kesejahteraan nelayan. Terjaganya sumberdaya ikan dan lingkungannya dapat dilakukan dengan memakai alat penangkapan ikan yang tidak destruktif, yang ramah lingkungan. Adanya penolakan nelayan terhadap alat ramah lingkungan yang ditawarkan pemerintah seperti jaring millenium perlu dikaji lebih lanjut dan bagaimana merubah nelayan dari kebiasaannya yang sudah dilakukan turun temurun. Pola "bottom-up" perlu dikembangkan agar masyarakat terlibat penuh dalam pemakaian alat tangkap ramah lingkungan, menimbulkan responsibility terhadap keberlangsungan sumberdaya ikan dan lingkungannya.

Peningkatan lapangan kerja perlu dilakukan salah satunya dengan pengalihan alat tangkap sesuai yang diperbolehkan peraturan perundang-undangan. Untuk merubah kebiasaan nelayan diperlukan pendampingan yang intensif mulai dari teknik penangkapan, permodalan maupun penguatan kelembagaan. Alternatif lain adalah dengan meninjau kembali praktek penangkapan cantrang yang selama ini dilakukan agar menjadi alat penangkapan ikan yang ramah lingkungan. Modifikasi alat tangkap cantrang seperti memperbesar size jaring agar tidak menangkap ikan-ikan yang kecil, perubahan tali selambar, pola penarikan jaring yang tidak mengganggu lingkungan. Selama ini pola penarikan jaring sering dianggap seperti pola alat penangkapan ikan trawl. Modifikasi perlu dilakukan agar jaring yang sudah ada yang dibeli dengan modal besar dapat dimanfaatkan sehingga tidak merugikan nelayan. Peningkatan lapangan kerja juga dapat dilakukan dengan meningkatkan pelatihan pemakaian alat tangkap ramah lingkungan, pemberian bantuan alat penangkapan ikan ramah lingkungan, pelatihan pengembangan usaha, kemudahan akses permodalan untuk membuka lapangan kerja baru, pola pembinaan dan pendampingan yang intensif.

Keberadaan alat tangkap dalam pemanfaatan sumberdaya ikan sangat erat kaitannya dengan peningkatan pendapatan yang diinginkan nelayan. Dengan demikian nelayan lebih cenderung memakai alat tangkap yang tingkat produktifitasnya tinggi, alat tangkap lebih murah, pengoperasian yang lebih mudah dan perawatan yang mudah serta tidak mahal. Cantrang memenuhi harapan dari nelayan sehingga tetap digunakan walau sudah ada pelarangan pemakaian cantrang. Penggunaan alat tangkap cantrang di Teluk Lampung yang umumnya banyak terumbu karangnya memang perlu dikendalikan jangan sampai merusak.

Cantrang mempunyai nilai yang paling tinggi dibandingkan dengan alat tangkap lain seperti jaring millenium, jaring klitik, jaring loang, jaring trammel, bubu ikan, pancing ulur, rawai dasar. Hal inilah yang membuat para nelayan tertarik dan terus mengoperasikan alat tangkap yang dilarang oleh KKP. Secara rinci terlihat bahwa alat tangkap yang dilarang ini memiliki produktivitas paling tinggi seperti cantrang dan arad. Produktivitas alat tangkap dilarang ini memiliki nilai di atas $50 \mathrm{~kg} \mathrm{/} \mathrm{setting}$ dibandingkan alat tangkap yang berkisar $2 \mathrm{~kg}$ / setting sampai $20 \mathrm{~kg}$ / setting.

Alat tangkap yang dilarang seperti cantrang, arad, jaring apollo, sondong dan garok merupakan alat penangkap ikan yang dominan menangkap ikan-ikan bernilai jual tinggi (nilai ekonomis penting) seperti cumi/sotong, udang dan rajungan. Sedangkan alat penangkap ikan pengganti seperti gillnet milenium menangkap ikan-ikan biasa yang bernilai jual rendah. Alat tangkap penggantinya belum ada yang sesuai untuk menggantikan target tangkapan utamanya yaitu cumi/sotong. Jika digantikan dengan gillnet millenium maka ikan target tangkapan utama berubah yang secara langsung juga merubah bentuk kapal dan wilayah penangkapan. Alat penangkap ikan yang dilarang memiliki nilai finansial sangat tinggi dibandingkan dengan alat penangkap ikan yang tidak dilarang atau rekomendasi pengganti. Nelayan tidak menyukai jaring millenium karena dianggap lebih mahal harganya, dalam pengoperasionalkannya mudah tersangkut dan hilang, biaya perawatan mahal karena sering ganti baru, dan hasil tangkapan yang nilainya di bawah cantrang.

Upaya pengembangan keberlanjutan sumberdaya ikan perlu dilakukan pemerintah, salah satunya melalui pelarangan cantrang yang diduga destruktif dan degradatif. Dengan demikian strategi pengembangan 
yang sudah didapatkan melalui analisis SWOT perlu dilakukan penerapan dengan komitmen yang tinggi dari semua pihak terkait, terutama nelayan sebagai pelaku utama yang akan mendapatkan dampak langsung dari penurunan sumberdaya ikan dan lingkungan yang berkorelasi linier dengan produktivitas penangkapan dan pendapatan.

\section{KESIMPULAN}

Kepatuhan nelayan terhadap pelarangan
alat tangkap cantrang masih rendah dibuktikan dengan masih beroperasionalnya kapal-kapal dengan cantrang di Teluk Lampung. Nelayan berpendapat bahwa cantrang tidak degradatif dan destruktif terhadap sumberdaya ikan dan lingkungannya berbeda dengan pendapat pemerintah menunjukkan masih lemahnya komunikasi. Sosialisasi alat tangkap ramah lingkungan belum efektif, sementara di sisi lain penerimaan yang diterima nelayan dari alat tangkap pengganti cantrang rendah. Penegakan hukum untuk pelanggaran alat tangkap yang dilarang masih diskriminatif, walaupun pelarangan alat tangkap cantrang dimaksudkan untuk menjaga keberlangsungan sumberdaya ikan. Strategi pengembangan keberlanjutan sumberdaya ikan melalui pelarangan alat tangkap cantrang adalah strategi Strength and Threat (ST) yaitu memanfaatkan kekuatan untuk mengurangi ancaman yang ada. Strategi yang diterapkan dalam kondisi ini adalah mendukung strategi diversifikasi atau kompetitif melalui strategi peningkatan kepatuhan nelayan dalam penggunaan alat tangkap ikan dan peningkatan lapangan kerja.

\section{DAFTAR PUSTAKA}

Aji, I.N., Wibowo, B.A. \& Asriyanto. 2013. Analisis faktor produksi hasil tangkapan alat tangkap cantrang di Pangkalan Pendaratan Ikan Bulu Kabupaten Tuban. Journal of Fisheries Resources Utilization Management and Technologi 2(4): 50-58.

Andryana, M.R. 2016. Strategi Adaptasi Nelayan dalam Menghadapi Peraturan Pelarangan Cantrang. Bogor: Institut Pertanian Bogor.

Bambang, N. 2006. Petunjuk Pembuatan dan Pengoperasian Cantrang dan Rawai
Dasar Pantai Utara Jawa Tengah. Semarang: Balai Besar Pengembangan Penangkapan Ikan.

Dahuri, R. 2003. Paradima Baru Pembangunan Indonesia Berbasis Kelautan. Bogor: Institut Pertanian Bogor.

Dunn, W.N. 1991. Pengantar Analisis Kebijakan Publik. Yogyakarta: Gadjah Mada University Press.

Kartodihardjo, H. 2017. Analisis Kebijakan Pengelolaan Sumberdaya Alam. Bogor: Firdaus Pressindo.

Rangkuti, F. 2006. Teknik Mengukur dan Strategi Meningkatkan Kepuasan Pelanggan. Jakarta: PT Gramedia Pustaka Utama.

Satria, A. 2015. Politik Kelautan dan Perikanan. Jakarta Yayasan Pustaka Obor Indonesia.

Sugiyono. 2018. Metode Penelitian Kuantitatif Kualitatif dan R \& D. Bandung: Alfabeta.

Sukmawati D. 2008. Struktur dan pola hubungan sosial ekonomi juragan dengan buruh di kalangan nelayan Pantai Utara Jawa Barat (Studi tentang simbiosis antara juragan dengan nelayan buruh di Pondok Bali Kecamatan Legon Kulon Kabupaten Subang). Jurnal Kependudukan Padjajaran, 10(1): 50-63

Wahab, S.A. 2012. Analisis Kebijakan: Dari Formulasi ke penyusunan Model-Model Implementasi Kebijakan Publik. Jakarta: Bumi Aksara.

Yapanani, E., Solichin, A. \& Wibowo, B.A. 2013. Kajian Hasil Tangkapan dan Tingkat Kesejahteraan Nelayan di Desa Aromarea Distrik Kosiwo, Kabupaten Sarui, Kepulauan Yapen, Papua. Aquares, 2(3):197-202.

Zamroni, A. 2015. Socio-economics status and adaptations of purse seine fishermen in Bali coastal village, Indonesia. International Journal of Marine Science, 5(20):1-16.

Zuliyati, E.N. 2015. Dampak Sosial dan Ekonomi atas Peraturan Menteri Kelautan dan Perikanan Nomor 2/PERMEN-KP/2015 (Studi Kasus Kecamatan Juwana Kabupaten Pati. Proceeding SENDI_U. Universitas Stikubank 